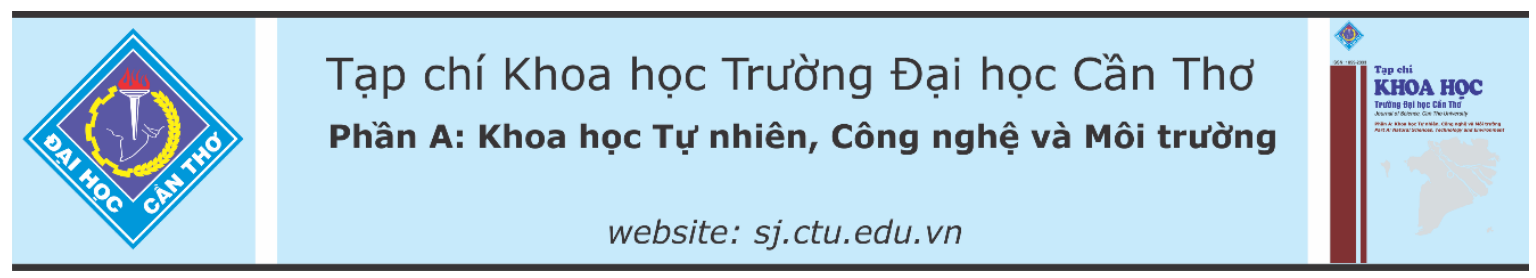

DOI:10.22144/ctu.jvn.2021.141

\title{
KHẢO SÁT HOẠT TÍNH KHÁNG SINH CỦA CAO CHIẾT TÙ LOÀI HẢI MIÊN Petrosia (Blue) SP.
}

\author{
Lưu Vũ Phương ${ }^{1}$, Quách Kim Huỳnh Hoa $^{1}$, Hà Tất Toàn ${ }^{1}$, Bùi Minh Phúc ${ }^{1}$, Lê Minh Trí ${ }^{1}$, \\ Võ Duy $\mathrm{An}^{2}$ và Tôn Nữ Liên Hương ${ }^{3 *}$ \\ ${ }^{1}$ Sinh viên Hoá Dược K44, Khoa Khoa học Tự nhiên, Truờng Đại học Cần Tho \\ ${ }^{2}$ Học viên cao học Hoá Hũu co K27, Khoa Khoa học Tự nhiên, Truờng Đại học Cần Tho' \\ ${ }^{3}$ Khoa Khoa hoc Tư nhiên, Truòng Đại hoc Cần Tho' \\ *Nguoòi chịu trách nhiệm về bài viết: Tôn Nũ Liên Hưong (email: tnlhuong@ctu.edu.vn)
}

\section{Thông tin chung:}

Ngày nhận bài: $23 / 06 / 2021$

Ngày nhân bài sưa: 27/08/2021

Ngày duyệt đăng: 29/10/2021

Title:

Investigation of antibiotic activity of sponge extract from Petrosia sp. (blue)

\section{Tù khóa:}

Kháng oxy hóa, kháng vi sinh vật kiểm định, Petrosia (blue) $s p$.

\section{Keywords:}

Antioxydant, antimicroorganism, Petrosia (blue) $s p$.

\begin{abstract}
Among the sponge species in Southwestern Vietnam, Petrosia sp. (blue) is relatively abundant and little studied. Surveying the biological activities of sponge harvested at a depth of $10 \mathrm{~m}$ in Kien Giang waters gave a lot of useful information. Testing for microorganism, 3 out of 4 samples, were well inhibited both Gram-negative and Gram-positive bacteria species; that are the total ethanol extract, the remaining ethanol extract, and dichloromethane extract, with $I C_{50}$ less than $40 \mu \mathrm{g} / \mathrm{mL}$. However, these extracts are neither antioxidant nor anti-Candida albican.
\end{abstract}

\section{TÓM TẮT}

Trong số các loài hải miên của vùng biển Tây Nam Việt Nam, loài Petrosia (blue) sp. có số lượng tương đối phong phú và ì được nghiên cứu. Khảo sát hoạt tính sinh học của các cao chiết tù̀ loài hải miên Petrosia (blue) sp. đuợc thu gom ở độ sâu khoảng $10 \mathrm{~m}$ tại vùng biển Kiên Giang đã cho nhũ̃ng thông tin hũu ich. Khi thư nghiệm kháng vi sinh vật, trong số 4 mẫu thư có 3 mẫu úc chế tốt các loài vi khuẩn Gram âm lẫn Gram duoong, một loài nấm men; đó là các mẫu cao ethanol tổng, cao ethanol còn lại, cao dichloromethane, với $I C_{50}<40 \mu \mathrm{g} / \mathrm{mL}$. Tuy nhiên, các cao của loài hải miên này không kháng oxy hóa và không có tác dụng với nấm men Candida albican.

\section{GIỚI THIỆU}

Nghiên cứu thành phần hoá học của các sinh vật biển thu hút sự quan tâm của các nhà khoa học vì đã phát hiện nhiều cấu trúc hợp chất biến dưỡng thứ cấp độc đáo trong cơ thể chúng mà không tìm thấy từ các nguồn sinh vật trên cạn (Ryu et al., 1996). Do điều kiện vật lý và hóa học đặc biệt của môi trường biển, các hợp chất hữu cơ được sinh tổng hợp đa dạng và có nhiều hoạt tính (Blunt et al., 2011). Hải miên (bọt biển) là một trong những động vật nguyên sinh cổ xưa nhất, là nguồn phân lập được gần $50 \%$ các hợp chất tự nhiên có hoạt tính sinh học (Gul \& Hamann, 2005). Hải miên được biết đến là nguồn hợp chất tự nhiên phong phú với hơn 5.000 loài có khắp vùng biển trên thế giới, có tiềm năng dược lý quý giá (Alarif et al., 2016). Trong số các loài cuả ngành Porifera, các nhà khoa học Đài Loan nghiên cứu Petrosia sp. và từ chiết xuất thô EtOAc (ethyl acetate) của nó (dịch chiết EtOAc thể hiện độc tính đáng kể với sáu dòng tế bào khối u ở người), đã tách các polyacetylene mạch hở khác nhau có hoạt tính 
sinh học mạnh gây độc tế bào ung thư trong thử nghiệm in vitro (Juan et al., 2014).

Việc khảo sát khả năng kháng oxy hóa và kháng vi sinh vật của các hợp chất phân lập từ loài hải miên còn ít được quan tâm và công bố so với khảo sát gây độc tế bào ung thư (Shen et al., 2006). Các loài hải miên rất có tiềm năng kháng oxy hóa và kháng khuẩn. Các pyrimidine phân lập từ loài hải miên tại Philippines thể hiện hoạt tính kháng khuẩn Gram âm tốt (Alma et al., 2013). Các dẫn xuất indole bao gồm bromoindole đã được phân lập từ hải miên vùng Thái Bình Dương: Rhopaloeides odorabile và Hyrtios sp. đều thể hiện kháng oxy hoá mạnh (Longeon et al., 2011). Cụ thể, dẫn xuất 5,6dibromo-L-hypaphorine được phân lập từ Hyrtios sp. có giá trị hấp thụ gốc oxy (oxygen radical absorbance capacity): ORAC $=0,22(\mu \mathrm{g}$ TE $/ \mathrm{mL}$ dung dịch mẫu), ngoài ra, cũng phân lập được sesquiterpene là aureol với $\mathrm{ORAC}=0,29$. Trong nghiên cứu gần đây, cao acetone từ loài Aaptos sp. ở vùng biển Indonesia thể hiện khả năng kháng oxy hoá tốt trong thử nghiệm DPPH (2,2-diphenyl-1picrylhydrazyl) với $\quad \mathrm{IC}_{50}=16,10 \mu \mathrm{g} / \mathrm{mL}$ (Fristiohady et al., 2020).

Nội dung bài báo này trình bày kết quả khảo sát sơ bộ khả năng oxy hoá và kháng vi sinh vật kiểm định nhằm cung cấp thêm chứng cứ khoa học về hoạt tính sinh học của loài hải miên Petrosia (blue) sp. dễ khai thác, thu gom được tại vùng biển Tây Nam Việt Nam.

\section{PHƯƠNG PHÁP, PHƯONG TIỆN NGHIÊN CÚU}

\subsection{Phương tiện, vật liệu nghiên cứu}

Mẫu vật liệu: hải miên thuộc chi Petrosia, tên là Petrosia (blue) sp., được thu gom tại độ sâu 5-10 m vùng biển Kiên Giang, Việt Nam, ở tọa độ $\mathrm{N}$ 09558'17.8"(E 10401'.34.4"), được định danh bởi TS. Thái Minh Quang công tác tại Viện Hải dương học Nha Trang. Mẫu tiêu bản số Sp10-2018, lưu tại phòng thí nghiệm Hữu cơ 2, khoa Khoa học tự nhiên, Trường Đại học Cần Thơ.

Hóa chất sử dụng điều chế cao chiết: ethanol, dichloromethane, $n$-hexane (Chemsol, Việt Nam) và dùng thử hoạt tính kháng oxy hóa: DPPH, DMSO (dimethyl sulfoxide), methanol (Merck). Chất hấp phụ Diaion HP-20 (Sigma-Aldrich). Bộ cô quay Heidolph, máy UV-Vis (Biotek), các dụng cụ phân tích vi sinh, micropipette và eppendorf.

\subsection{Phương pháp nghiên cứu}

Thực hiện định danh khoa học mẫu nguyên liệu và chiết cao ethanol, sau đó dùng phương tiện chiết lỏng lỏng để phân đoạn cao theo độ phân cực khác nhau, tại khoa Khoa học tự nhiên (KHTN)

Thử nghiệm kháng oxy hoá được thực hiện tại khoa KHTN, trường Đại học Cần Thơ

Thử nghiệm kháng vi sinh vật kiểm định theo phương pháp pha loãng nồng độ trên môi trường lỏng, thực hiện tại phòng Hoá Sinh ứng dụng, Viện Hoá học, Viện Hàn lâm Khoa học Công nghệ Việt Nam.

\subsection{1. Điều chế cao chiết}

Mẫu hải miên Petrosia (blue) sp. sau khi thu về được rửa thật sạch để ráo, tiếp theo ngâm dầm, chiết kiệt với dung môi ethanol. Dịch chiết sau khi cô quay loại bớt dung môi được cao chiết ethanol tổng và được loại muối qua cột Diaion. Thực hiện chiết phân đoạn lỏng lỏng với các dung môi có độ phân cực khác nhau và cô đặc dung dịch thu được các cao chiết, gồm cao ethanol tổng (EtOH tổng), cao $n$ hexane (cao Hex), cao dichoromethane (cao DC) và cao ethanol còn lại (EtOH còn lại).

\subsubsection{Khảo sát khả năng kháng oxi hóa bằng phương pháp trung hòa gốc tư do DPPH}

2,2-Diphenyl-1-picrylhydrazyl (DPPH) là chất tạo ra gốc tự do được dùng để thực hiện sàng lọc tác dụng chống oxy hóa của các chất nghiên cứu. Hoạt tính kháng oxy hóa thể hiện qua việc làm giảm màu của $\mathrm{DPPH}$, được xác định bằng phương pháp đo mật độ quang ở bước sóng $\lambda=517 \mathrm{~nm}$.

Cách tiến hành: Pha dung dịch DPPH có nồng độ $1 \mathrm{mM}$ trong methanol. Chất thử được pha trong DMSO 100\% sao cho cuối cùng đạt được một dãy các nồng độ theo cấp số nhân từ 4 đến $256 \mu \mathrm{g} / \mathrm{mL}$. Để thời gian phản ứng 30 phút ở $37^{\circ} \mathrm{C}$, đọc mật độ hấp phụ của $\mathrm{DPPH}$ chưa phản ứng bằng máy đọc Biotek ở bước sóng $517 \mathrm{~nm}$. (Cuendet et al., 1997; Burits \& Bucar, 2000; Marxen et al., 2007) Từ đường chuẩn biểu thị mối tương quan giữa nồng độ DPPH và mật độ quang học lâp được có thể ngoại suy các giá trị phần trăm bắt gốc tự do, kháng oxy hoá.

\% bắt gốc tự do $\mathrm{DPPH}(\mathrm{SC} \%)$ của mẫu thử được tính theo công thức sau:

$$
\mathrm{SC} \%=\left(\mathrm{OD}_{\text {trắng }}-\mathrm{OD} \text { mẫu thử }\right) / \mathrm{OD}_{\text {trắng }}
$$

Trong đó, $\mathrm{OD}$ trắng: giá trị mật độ quang đo của mẫu trắng; 


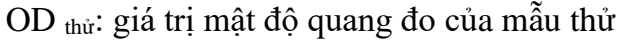

$\mathrm{EC}_{50}$ được tính theo giá trị $\mathrm{SC}$ tương quan với các nồng độ khác nhau của chất thử nghiệm, thí nghiệm được lặp lại với $\mathrm{n}=3$.

\subsubsection{Khảo sát hoạt tính kháng vi sinh vật kiểm dịnh}

Các chủng vi sinh vật kiểm định: Bacillus subtilis (ATCC 6633): là trực khuẩn Gram dương, sinh bào tử, thường không gây bệnh. Staphylococcus aureus (ATCC 13709): cầu khuẩn Gram dương, gây mủ các vết thương, vết bỏng, gây viêm họng, nhiễm trùng có mủ trên da và các cơ quan nội tạng Lactobacillus fermentum (N4): vi khuẩn Gram dương, là loại vi khuẩn đường ruột lên men có ích, thường có mặt trong hệ tiêu hóa của người và động vật.

Escherichia coli (ATCC 25922): vi khuẩn Gram âm, gây một số bệnh về đường tiêu hóa như viêm dạ dày, viêm đại tràng, viêm ruột, viêm lỵ trực khuẩn. Pseudomonas aeruginosa (ATCC 15442): vi khuẩn Gram âm, trực khuẩn mủ xanh, gây nhiễm trùng huyết, các nhiễm trùng ở da và niêm mạc, gây viêm đường tiết niệu, viêm màng não, màng trong tim, viêm ruột. Salmonella enterica: vi khuẩn Gram âm, gây bệnh thương hàn, nhiễm trùng đường ruột ở người và động vật. Candida albicans (ATCC 10231): nấm men, thường gây bệnh tưa lưỡi ở trẻ em và các bệnh phụ khoa.

Các kháng sinh thương mại được sử dụng như chất tham chiếu gồm kháng sinh Ampicillin, Cefotaxim và kháng nấm Nystatin. Môi trường nuôi cấy: MHB (Mueller-Hinton Broth), MHA (MuellerHinton Agar); TSB (Tryptic Soy Broth); TSA (Tryptic Soy Agar) cho nuôi cấy vi khuẩn; SDB (Sabourand-2\% dextrose broth) và SA (Sabourand$4 \%$ dextrose agar) cho nuôi cấy nấm.

Phương pháp pha loãng nồng độ trên môi trường lỏng được sử dụng trong thử nghiệm hoạt tính kháng vi sinh vật kiểm định, đánh giá mức độ kháng khuẩn mạnh yếu của các mẫu thử thông qua độ đục của môi trường nuôi cấy. Các giá trị thể hiện hoạt tính là $\mathrm{IC}_{50}$ (50\% Inhibitor Concentration: nồng độ ức chế 50\%), MIC (Minimum Inhibitor Concentration: nồng độ ức chế tối thiểu), MBC (Minimum Bactericidal Concentration: nồng độ diệt khuẩn tối thiểu) và MFC (Minimum Fungicidal Concentration: nồng độ diệt nấm tối thiểu), (Ania et al., 2017; Cos et al., 2006; Hadacek \& Greger, 2007)

Cách tiến hành:

\section{Pha loãng mẫu thư:}

Mẫu ban đầu được pha loãng 2 bước trong DMSO $100 \%$ và nước cất tiệt trùng thành một dãy 4 nồng độ. Nồng độ thử cao nhất trong thử nghiệm là $256 \mu \mathrm{g} / \mathrm{mL}$ với dịch chiết.

\section{Thư hoạt tinh:}

- Vi sinh vật kiểm định được lưu giữ ở $-80^{\circ} \mathrm{C}$. Trước khi thí nghiệm, vi sinh vật kiểm định được hoạt hóa bằng môi trường nuôi cấy sao cho nồng độ vi khuẩn đạt $5.10^{5} \mathrm{CFU} / \mathrm{mL}$;

nồng độ nấm đạt $10^{3} \mathrm{CFU} / \mathrm{mL}$.

- Lấy $10 \mu \mathrm{l}$ dung dịch mẫu thử ở các nồng độ vào đĩa 96 giếng, thêm $190 \mu 1$ dung dịch vi khuẩn và nấm đã được hoạt hóa ở trên, ủ ở $37^{\circ} \mathrm{C} / 16-24$ giờ.

\section{Xư lý kết quả}

- Giá trị MIC được xác định tại giếng có nồng độ chất thử thấp nhất ức chế hoàn toàn sự phát triển của vi sinh vật. Giá trị $\mathrm{MBC} / \mathrm{MFC}$ được xác định bằng cách cấy dung dịch tại giếng đã xác định có giá trị MIC lên đĩa thạch và không có vi sinh vật kiểm định nào mọc trở lại sau 24 giờ. $\mathrm{IC}_{50}$ được xác định thông qua giá trị \% ức chế vi sinh vật phát triển và phần mềm máy tính Rawdata.

$$
\begin{aligned}
& \% \text { ức chế tế bào }=\left(\mathrm{OD}_{\text {chúng }(+)}-\mathrm{OD}_{\text {mẫu thử }}\right) /( \\
& \left.\mathrm{OD}_{\text {chứng }(+)}-\mathrm{OD}_{\text {chứng (-) }}\right) \times 100 \%
\end{aligned}
$$

$$
\mathrm{IC}_{50}=\operatorname{High}_{\text {Conc }}-\frac{\left(\mathrm{High}_{\text {Inh\% }}-50\right) \times\left(\mathrm{High}_{\text {Conc }}-\mathrm{Low}_{\text {Conc }}\right)}{\operatorname{High}_{\text {Inh\% }}-\mathrm{LOW}_{\text {Inh\% }}}
$$

(Trong đó, $\mathrm{High}_{\mathrm{Con} /} / \mathrm{Low}_{\mathrm{Conc}}$ : chất thử ở nồng độ cao/chất thử thấp ở nồng độ thấp; $\mathrm{High}_{\text {Inh } \%} / \mathrm{Low}_{\text {Inh } \%}$ : \% ức chế ở nồng độ cao/\% ức chế ở nồng độ thấp).

- Đánh giá hoạt tính: dịch chiết có $\mathrm{IC}_{50}<100$ $\mu \mathrm{g} / \mathrm{mL}$; chất sạch có $\mathrm{IC}_{50}<25 \mu \mathrm{M}$. Hoặc mẫu thô có $\mathrm{MIC} \leq 200 \mu \mathrm{g} / \mathrm{mL}$; chất sạch có $\mathrm{MIC} \leq 50 \mu \mathrm{g} / \mathrm{mL}$.

\section{Chất tham chiếu}

- Kháng sinh Ampicillin cho các chủng vi khuẩn Gram dương với các giá trị $\mathrm{IC}_{50}$ trong khoảng $0,001-0,500 \mu \mathrm{g} / \mathrm{mL}$; các giá trị MIC trong khoảng $0,004-1,200 \mu \mathrm{g} / \mathrm{mL}$.

- Kháng sinh Cefotaxim cho các chủng vi khuẩn Gram âm với các giá trị $\mathrm{IC}_{50}$ trong khoảng $0,025-15,75 \mu \mathrm{g} / \mathrm{mL}$; với giá trị MIC trong khoảng $0,05-19,5 \mu \mathrm{g} / \mathrm{mL}$. 
- Kháng nấm Nystatin cho chủng nấm Candida với giá trị $\mathrm{IC}_{50}$ trong khoảng $2-2,5 \mu \mathrm{g} / \mathrm{ml}$; với giá trị MIC trong khoảng 2,8-5,0 $\mu \mathrm{g} / \mathrm{mL}$.

\section{KẾT QUẢ VÀ THẢO LUẬN}

\subsection{Kết quả thử hoạt tính kháng oxi hóa}

Thực hiện pha loãng các mẫu cao theo các thang nồng độ tăng dần từ 4 đến 16,64 và $256 \mu \mathrm{g} / \mathrm{mL}$ và ở mỗi nấc nồng độ cho mẫu cao pha với DPPH để hình thành mẫu thử, đo độ hấp thụ quang và xây dựng đồ thị tương quan giữa mật độ quang và nồng độ mẫu như Hình 1.

Từ phần trăm bắt gốc tự do DPPH của mẫu thử có được, đã tính giá trị $\mathrm{EC}_{50}$ của các mẫu sau 3 lần thử nghiệm. Kết quả thử nghiệm được tóm tắt trình bày trong Bảng 1 .

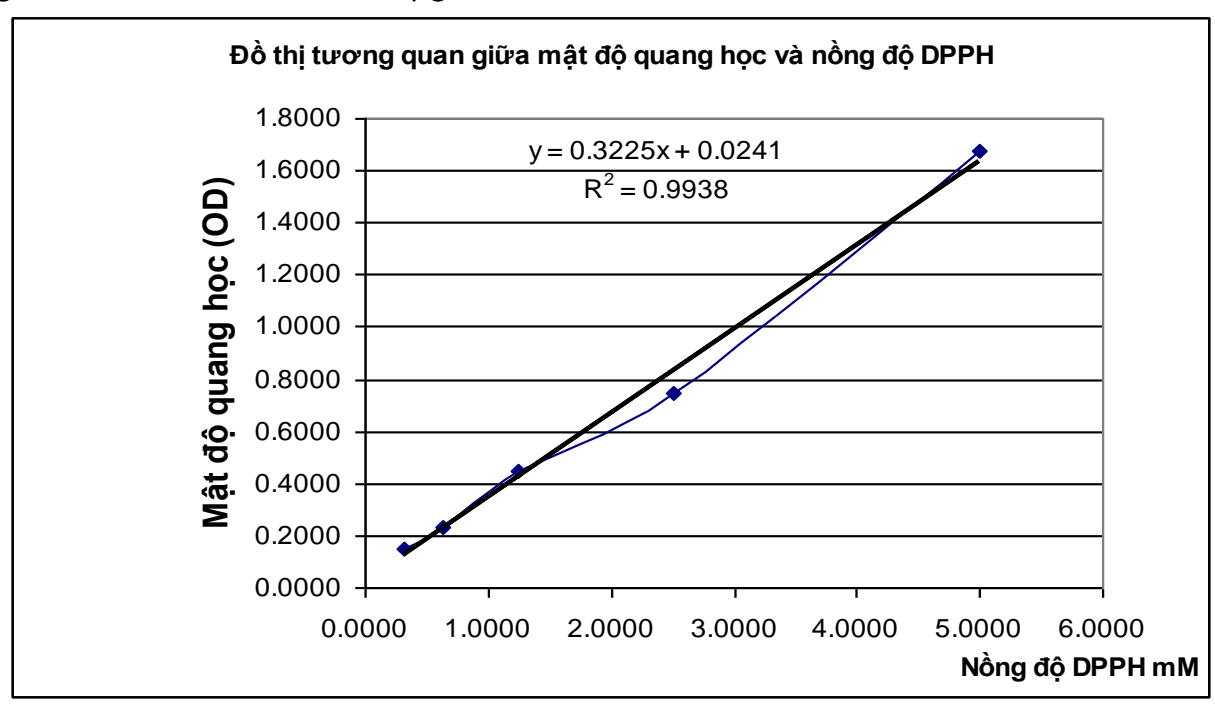

Hình 1. Đồ thị tương quan giữa mật độ quang và nồng độ DPPH

Bảng 1. Khả năng bắt giữ gốc tự do (\%) theo từng nồng độ của các cao chiết

\begin{tabular}{|c|c|c|c|c|c|}
\hline \multirow{2}{*}{ Tên mẫu } & \multicolumn{4}{|c|}{ Khả năng bắt giữ gốc tự do $(\%)$ theo nồng độ thử nghiệm } & \multirow{2}{*}{$\begin{array}{r}\mathrm{EC}_{50} \\
(\mu \mathrm{g} / \mathrm{mL})\end{array}$} \\
\hline & $256 \mu \mathrm{g} / \mathrm{mL}$ & $64 \mu \mathrm{g} / \mathrm{mL}$ & $16 \mu \mathrm{g} / \mathrm{mL}$ & $4 \mu \mathrm{g} / \mathrm{mL}$ & \\
\hline Cao EtOH tổng & $18 \%$ & $0 \%$ & $0 \%$ & $0 \%$ & $>256$ \\
\hline Cao EtOH còn lại & $21 \%$ & $7 \%$ & $0 \%$ & $0 \%$ & $>256$ \\
\hline Cao DC & $19 \%$ & $3 \%$ & $0 \%$ & $0 \%$ & $>256$ \\
\hline Cao Hex & $17 \%$ & $0 \%$ & $0 \%$ & $0 \%$ & $>256$ \\
\hline
\end{tabular}

Theo bảng kết quả, cao chiết của hải miên Petrosia (blue) sp không bắt giữ gốc tự do ở nồng độ nhỏ, các giá trị $\mathrm{EC}_{50}$ của cao lớn hơn $256 \mu \mathrm{g} / \mathrm{mL}$, không có khả năng kháng oxy hóa ứng dụng được trong thực tế.

Trong cùng chi Petrosia, chỉ có loài Petrosia contignata có khả năng kháng oxi hóa yếu, với giá trị $\mathrm{IC}_{50}=89,59 \mu \mathrm{g} / \mathrm{mL}$ (Abdillah et al., 2013). Trong các loài khác chi Petrosia, như hải miên thuộc họ Superitade ở khu vực biển Philippine, loài Aaptos suberitoides kháng oxy hoá tốt $\mathrm{IC}_{50}=27,42$ $\mu \mathrm{g} / \mathrm{mL}$, (Alma et al., 2013).

\subsection{Kết quả thử hoạt tính kháng vi sinh vật}

Hiệu quả ức chế các chủng vi sinh vật kiểm định được trình bày ở Bảng 2 . Kết quả cho thấy, trừ cao Hex, các cao phân cực trung bình đến phân cực mạnh của hải miên Petrosia (blue) sp. đều có khả năng ức chế đối với 6 dòng vi khuẩn: $S$. aureus, $B$. subtilis, L. fermentum, S. enterica, E. coli và $P$. aeruginosa ở các nồng độ khác nhau. Đặc biệt cao DC ít ảnh hưởng tới lợi khuẩn Gram dương $L$. fermentum. Các cao phân cực như: cao EtOH tổng, cao EtOH còn lại sau khi tách loại các chất phân cực yếu, đều cho kết quả ức chế mạnh vi khuẩn Gram dương, $\mathrm{IC}_{50}<28,9 \mu \mathrm{g} / \mathrm{mL}$, mức nồng độ áp dụng rất tốt vào thực tế. 
Bảng 2. Hiệu quả ức chế các chủng vi sinh vật kiểm định của các loại cao chiết

\begin{tabular}{|c|c|c|c|c|c|c|c|c|}
\hline \multirow{2}{*}{ Tên mẫu } & \multirow{2}{*}{$\begin{array}{l}\text { Giá } \\
\text { trị }\end{array}$} & \multicolumn{3}{|c|}{$\begin{array}{l}\text { Nồng độ ức chế VSV } \\
\text { Gram dương }(\mu \mathrm{g} / \mathrm{mL})\end{array}$} & \multicolumn{3}{|c|}{$\begin{array}{c}\text { Nồng độ ức chế VSV Gram âm } \\
(\mu \mathrm{g} / \mathrm{mL})\end{array}$} & \multirow{2}{*}{$\begin{array}{r}\begin{array}{c}\text { Nấm } \\
\text { men }\end{array} \\
C \\
\text { albican }\end{array}$} \\
\hline & & $\begin{array}{r}S . \\
\text { aureus } \\
\end{array}$ & $\begin{array}{r}B . \\
\text { subtilis } \\
\end{array}$ & $\begin{array}{r}L . \\
\text { fermentum }\end{array}$ & E. coli & $\begin{array}{r}S . \\
\text { enterica } \\
\end{array}$ & $\begin{array}{r}P . \\
\text { aeruginosa } \\
\end{array}$ & \\
\hline \multirow{2}{*}{$\begin{array}{l}\mathrm{Cao} \mathrm{EtOH} \\
\text { tổng }\end{array}$} & $\overline{\mathrm{IC}}$ & 12,60 & 15,33 & 12,17 & 10,00 & 141,84 & 34,96 & $>256$ \\
\hline & MIC & 256 & 256 & 256 & 16,00 & $>256$ & 64,00 & $>256$ \\
\hline \multirow{2}{*}{$\begin{array}{l}\text { Cao EtOH } \\
\text { còn lại }\end{array}$} & $\mathrm{IC}_{50}$ & 11,08 & 28,86 & 43,00 & 9,55 & 117,58 & 35,67 & $>256$ \\
\hline & MIC & 64,00 & 256 & $>256$ & 16,00 & $>256$ & 64,00 & $>256$ \\
\hline \multirow{2}{*}{ Cao DC } & $\mathrm{IC}_{50}$ & 99,26 & $>256$ & 218,28 & 154,22 & $>256$ & $>256$ & $>256$ \\
\hline & MIC & $>256$ & $>256$ & $>256$ & $>256$ & $>256$ & $>256$ & $>256$ \\
\hline \multirow{2}{*}{ Cao Hex } & IC & $>256$ & $>256$ & $>256$ & $>2$ & $>256$ & $>256$ & $>256$ \\
\hline & MIC & $>256$ & $>256$ & $>256$ & $>256$ & $>256$ & $>256$ & $>256$ \\
\hline
\end{tabular}

Đối với các khuẩn Gram âm gây các bệnh lý bất lợi đường ruột, các cao phân cực đều có khả năng kháng khuẩn tốt, trong đó cao ethanol tổng và cao ethanol còn lại ức chế mạnh vi khuẩn Escherichia coli $\left(\mathrm{IC}_{50}<10,0 \mu \mathrm{g} / \mathrm{mL}\right)$ và trực khuẩn mủ xanh $P$. aeruginosa, $\left(\mathrm{IC}_{50}<35,9 \mu \mathrm{g} / \mathrm{mL}\right)$, mức nồng độ có giá trị ứng dụng tốt vào thực tế. Tất cả các cao không ức chế chủng nấm men Candida albican.

Nhìn chung, khả năng ức chế tất cả các chủng vi khuẩn Gram dương lẫn Gram âm rất mạnh ở hai loại cao phân cực là cao ethanol tổng và ethanol còn lại (cao tổng đã loại béo), khả năng này chỉ hơi yếu đối với chủng khuẩn Salmonella enterica gây bệnh tả lỵ. Các giá trị $\mathrm{IC}_{50}$ của 2 loại cao ethanol này khoảng $9,55-10,0(\mu \mathrm{g} / \mathrm{mL})$ và $\mathrm{MIC} 16,0(\mu \mathrm{g} / \mathrm{mL})$ xấp xỉ với các số liệu của chất tham chiếu Cefatoxim ức chế Escherichia coli, chứng tỏ chế phẩm từ hải miên Petrosia blue rất nhiều tiềm năng ứng dụng là kháng sinh có giá trị an toàn sinh học.

Hải miên là sinh vật biển không có giá trị thương phẩm như san hô, nhưng có khả năng khánh sinh mạnh như trường hợp của loài Petrosia (blue) sp. này là một nguồn lợi đặc thù của vùng biển Việt Nam.

\section{KẾT LUẬN}

Nghiên cứu trên các cao chiết phân cực khác nhau của loài hải miên Petrosia (blue) sp. cho những kết quả bước đầu rất khả quan. Trong số 4 cao thử nghiệm, có 3 loại gồm cao dichloromethane, cao ethanol sau khi loại béo và cao ethanol tổng thể hiện khả năng kháng khuẩn tốt với cả 3 chủng khuẩn Gram âm gây bệnh nguy hiểm, ức chế mạnh 2 khuẩn Gram dương, ức chế tương đối yếu với vi khuẩn đường ruột Lactobacillus fermentum. Cao ethanol tổng có khả năng kháng sinh tốt nhất với 3 chủng khuẩn Gram âm là Staphylococcus aureus $\left(\mathrm{IC}_{50}=\right.$ $11,08 \mu \mathrm{g} / \mathrm{mL})$, Escherichia coli $\left(\mathrm{IC}_{50}=9,55 \mu \mathrm{g} / \mathrm{mL}\right)$, Pseudomonas aeruginosa $\left(\mathrm{IC}_{50}=35,67 \mu \mathrm{g} / \mathrm{mL}\right)$. Tuy các cao chiêt của loài hải miên Petrosia sp. (blue) không thể hiện khả năng kháng oxi hóa và kháng nấm men, nhưng đây là một nguồn cung cấp các hợp chất có khả năng kháng vi sinh vật tốt, có tiềm năng ứng dụng trong đời sống.

\section{LỜI CẢM ƠN}

Nhóm tác giả trân trọng cảm ơn Trường Đại học Cần Thơđã cấp kinh phí thực hiện đề tài Sinh viên NCKH, mã số TSV2021-53, Bộ môn Hóa học, Khoa Khoa học tự nhiên đã hỗ trợ thiết bị nghiên cứu, chân thành cảm ơn TS. Thái Minh Quang (Viện Hải dương học Nha Trang) đã nhiệt tình hỗ trợ định danh các loài hải miên.

\section{TÀI LIỆU THAM KHẢO}

Abdillah, S., Nurhayati, A., Nurhatika, S., Setiawan, E. \& Heffen, W. L. (2013). Cytotoxic and antioxidant activities of marine sponge diversity at Pecaron Bay Pasir Putih Situbondo East Java, Indonesia. Journal of Pharmacy Research, 6(7), 685-689.

Alarif, W. M., Lihaibi, S. S. A., Ghandourah, M. A., Orif, M. I., Basaif, S. A. \& Ayyad, S. E. N. (2016). Cytotoxic scalarane-type sesterterpenes from the Saudi Red Sea sponge Hyrtios erectus. J. Asian Natural Product Research, 18(6), 611-617.

Alma, M., Quiao, D. \& Mylene, M. U. (2013). Pyrimidines from the Philippine marine sponge Aaptos suberitoides, International Journal of Scientific \& Engineering Research, 4(1), 1-4.

Ania, O. P., Arranz, J. C. E., Beaven, M., Renato P. R., Yordania, M. G., Miladis, I. C. P., Maury, G. L., Macedo, M. B., Cos, P., Tavares, J. F. \& Silva, M. S. D. (2017). Bioassay-guided-in vitro study of the antimicrobial and cytotoxic properties of the leaves from Excoecaria lucida $\mathrm{Sw}$. Pharmacognosy Research, 9(4), 396-400.

Blunt, J. W., Copp, B. R., Munro, M. H., Northcote, P. T. \& Prinsep, M. R. (2011). Marine natural products. Natural Product Report, 28(2), 196-268. 
Burits, M. \& Bucar, F. (2000). Antioxidant activity of Nigella sativa essential oil. Phytotherapy Research, 14(5), 323-328. DOI: 10.1002/10991573(200008)

Cos, P., Vlietinck, A. J., Vanden, B. D. \& Maes, L. (2006). Anti-infective potential of nature products: How to develop a stronger in vitro 'proof-of-concept'. Journal of Ethnopharmacology, 106(3), 290-302. DOI: 10.1016/j.jep.2006.04.003.

Cuendet, M., Hostettmann, K. \& Potterat, O. (1997). Iridoid glucosides with free radical scavenging properties from Fagraea blumei, Helvetica Chimica Acta, 80(4), 1144-1152.

Fristiohady, A., Sadarun, A., Wahyuni, W., Malaka, M. H., Ahmad, F., Malik, F., Purnama, L. O. M. J. \& Sahidin, I. (2020). Isolation and identification of secondary metabolite acetone extract Aaptos sp. and its antioxidant properties and acute toxicity. Journal of Applied Pharmaceutical Science, 10(06), 81-89.

Gul, W. \& Hamann, M. T. (2005). Indole alkaloid marine natural products: An established source of cancer drug leads with considerable promise for the control of parasitic, neurological and other diseases. Life Science, 78(5), 442-453. doi: 10.1016/j.lfs.2005.09.007

Hadacek, F. \& Greger, H. (2000). Test of antifungal natural products: Methodologies, comparability of results and assay choise, Phytochemical Analysis, 11(3), 137-147.
Juan, Y. S.; Lee, C. C., Tsao C. W., Lu M. C, Mohamed E. S, Shih H. C., Chen C. Y, Wu Y. C., $\& S u$ J. H. (2014). Structure elucidation and cytotoxic evaluation of new polyacetylenes from a marine sponge Petrosia sp. Int. J. Mol. Sci., 15(9), 16511-16521. https://doi.org/10.3390/ijms150916511

Longeon, A., Brent, R., Copp, E. Q., Roué, M., Kientz, B., Cresteil, T., Petek, S., Debitus, C. \& Bourguet-Kondracki, M. L. (2011). Bioactive Indole derivatives from the South Pacific marine sponges Rhopaloeides odorabile and Hyrtios sp. Marine drugs, 9(5), 879-888. DOI: $10.3390 / \mathrm{md} 9050879$

Marxen, K., Vanselow, K. H., Lippemeier, S., Hintze, R., Ruser, A., \& Hansen, U. P. (2007). Determination of DPPH radical oxidation caused by methanolic extracts of some microalgal species by linear regression analysis of spectrophotometric measurements. Sensors, 7(10), 2080-2095.

Ryu, G., Matsunaga, S., \& Fusetani, N. (1996). Three new cytotoxic sesterterpenes from the marine sponge Hyrtios cf. erectus. Journal of Natural Product, 59(5), 515-517.

Shen, Y. C., Liaw, C., Ho, J. R., Khalil, A. T., \& Kuo, Y. H. (2006). Isolation of aureol from Smenospongia sp. and cytotoxic activity of some aureol derivatives. Nat. Prod. Res., 20(6), 578585. https://doi.org/10.1080/14786410500185253. 